\title{
СОГЛАШЕНИЕ О ВЫХОДЕ ВЕЛИКОБРИТАНИИ ИЗ ЕС: ПЕРСПЕКТИВЫ РАТИФИКАЦИИ
}

Аннотация. Переговоры об условиях выхода Великобритании из Европейского союза длились более полутора лет. Обе сторонь шли на уступки для достижения желаемого результата. Как и ожидалось, Евросоюз смог добиться выполнения практически всех своих требований, а Британии пришлось отступить от части своих первоначальных предложений. Однако согласованный текст вызвал недовольство в британском политическом сообществе. В итоге перспективы его ратификации в Палате общин остаются весьма туманными. Отказ от ратификаџии грозит политическим хаосом для Великобритании и возможным выходом «без сделки», что объективно не отвечает интересам сторон.

Ключевые слова: брекзит, Европейский союз, Великобритания, ирландская граница, соглашение о выходе, Палата общин.

Переговоры о выходе Великобритании из Евросоюза длились полтора года и закончились в ноябре 2018 г. заключением соглашения, фиксирующим условия развода. Одновре́менно стороны подписали политическую декларацию о будущих отношениях. Однако перспективы ратификации соглашения остаются туманными из-за разногласий в британском парламенте. Чтобы понять, чем недовольно большинство членов Палаты общин, нужно выяснить, чего смогла добиться каждая из сторон на переговорах, исходя из своих первоначальных требований.

\section{Первоначальные позиции сторон}

В январе 2017 г. правительство Терезы Мэй сформулировало свою позицию в отношении формы выхода из ЕС ${ }^{1}$. Британия хотела покинуть Единый внутренний рынок (ЕВР) и Таможенный союз (ТС) Европейского союза, чтобы проводить собственную торговую политику и отказаться от свободы передвижения граждан, права и юрисдикции Суда ЕС. При этом британское правительство неоднократно заявляло ${ }^{2}$ о желании поддерживать особые отношения с Евросоюзом, создать широкую зону свободной торговли и сохранить своё участие в ряде проектов в сфере юстиции и внутренних дел. Изначально Лондон предполагал параллельно вести переговоры об условиях выхода из ЕС и о будущем формате отношений.

В апреле 2017 г. Европейский совет опубликовал основные принципы будущих перего-

СБабынина Людмила Олеговна - кандидат политических наук, ведущий научный сотрудник, руководитель Центра политической интеграции Института Европы РАН. Адрес: 125009, Россия, Москва, ул. Моховая, д. 11 , стр. 3 ; доцент факультета мировой политики МГУ им. М.В. Ломоносова. E-mail: lbabynina@yandex.ru.

DOI: http://dx.doi.org/10.15211/vestnikieran620181419

${ }^{1}$ Plan for Britain. The government's negotiating objectives for exiting the EU: PM speech. URL: https://www.gov. uk/government/speeches/the-governments-negotiating-objectives-for-exiting-the-eu-pm-speech.

${ }^{2}$ Среди прочих документов такая позиция была сформулирована в «плане Чекерс». HM Government. The future relationship between the United Kingdom and the European Union. Jule 2018. URL: https://assets.publishing.service. gov.uk/government/uploads/system/uploads/attachment_data/file/725288/The_future_relationship_between_the_United _Kingdom_and_the_European_Union.pdf. 
воров ${ }^{1}$, согласно которым на их первой фазе должны быть решены три вопроса - обеспечение прав граждан ЕС, проживающих в Соединённом Королевстве, и британцев в странах Евросоюза, выполнение финансовых обязательств со стороны Великобритании и обустройство прозрачной границы между Северной Ирландией и Республикой Ирландия. После достижения прогресса по этим вопросам стороны смогут перейти ко второй фазе переговоров о будущем сотрудничестве в торговой и других сферах. Лондону пришлось согласиться с таким подходом. Это стало первой уступкой правительства Т. Мэй.

\section{Кто вел переговоры}

Для ведения переговоров стороны создали специальные структуры. Так, в британском правительстве появилось министерство по выходу из ЕС, которое вначале возглавил известный евроскептик Дэвид Дэвис. Позиция министерства на переговорах отражала подходы правительства. В Британии, в случае появления принципиальных разногласий между премьером и министрами, последние, как правило, уходят в отставку. Так случилось с Дэвисом в июле 2018 г., когда был согласован «план Чекерс», и с его приемником Домеником Раабом, когда было подготовлено итоговое соглашение о выходе Великобритании из Европейского союза. За период переговоров были и другие громкие отставки в правительстве Т. Мэй, которые подтверждали глубокие разногласия по тому, как именно должен быть реализован брекзит.

В переговорном процессе были задействованы и все основные институты ЕС, которые демонстрировали слаженную работу и консолидированный подход. Европейский совет формулировал основные принципы и цели переговоров, принимал базовые документы и решения, одобрил проект соглашения о выходе Великобритании. После ратификации в обоих парламентах Европейский совет должен будет одобрить итоговый текст. Великобритания не при-нимает участия в заседаниях Европейского совета, на которых обсуждаются позиции ЕС на переговорах, а также будущие реформы Евросоюза. Европейский совет дал Комиссии мандат на проведение переговоров и утвердил главным представителем ЕС на них Мишеля Барнье ${ }^{2}$. Комиссия, в лице аппарата Барнье, непосредственно вела переговоры, консультируясь с Советом министров ЕС и Европарламентом. Последний на переговорах представлял Ги Верхофстадт, которого приглашали к участию в заседаниях Европейского совета, когда рассматривали вопросы, посвященные брекзиту. Следует отметить, что из всех задействованных институтов именно Европарламент занимал наиболее жёсткую позицию в отношении Британии, особенно в отношении соблюдения прав граждан ${ }^{3}$. Кроме того, Европейский парламент также должен будет одобрить итоговое соглашение после его ратификации в британском парламенте.

Особую роль в переговорах о выходе Великобритании из Европейского союза занимает Суд $\mathrm{EC}^{4}$. С одной стороны, границы применения юрисдикции Суда ЕС, особенно в отношении соблюдения прав граждан и соблюдения стандартов ЕС, стали одним из самых обсуждаемых вопросов, т.к. здесь стороны занимают диаметральные позиции. С другой стороны, пока Соединённое Королевство находится в составе Союза, на него распространяется деятельность Суда ЕС, что потенциально может вызывать некоторые проблемы. Например, если

\footnotetext{
${ }^{1}$ European Council (Art. 50) guidelines following the United Kingdom's notification under Article 50 TEU. URL: http://www.consilium.europa.eu/en/press/press-releases/2017/04/29-euco-brexit-guidelines/

${ }_{2}$ The European Council. Infographics - brexit process URL: http://www.consilium.europa.eu/en/infographics/brexitprocess/

3 The European Parliament. Red lines on brexit negotiations. URL: http://www.europarl.europa.eu/news/en/headlines/ priorities/brexit/20170329IPR69054/red-lines-on-brexit-negotiations.

${ }_{4}^{4}$ Gostyńska-Jakubowska A. (2017) Brexit maze: The role of EU institutions in the negotiations. Centre for European Reform (CER). London. URL: https://cer.eu/sites/default/files/pb_brexit_institutions_5.7.17.pdf.
} 
Ко-миссия начнёт расследование в отношении имплементации какого-либо закона ЕС в Британии до её выхода, а решение Суда будет принято после даты брекзита, то, с точки зрения $\mathrm{EC}$, постановление всё равно должно быть выполнено. Очевидно, что британское правительство придерживается иного мнения.

В ходе переговоров стороны придерживались принципа прозрачности, публиковали все официальные документы, выступления участников переговоров и т.д.

\section{Уступки сторон}

К концу 2017 г. стороны значительно продвинулись в решении вопросов, связанных с обеспечением прав граждан ЕС, проживающих в Соединённом Королевстве, после брекзита. Британия также дала гарантии исполнения финансовых обязательств в рамках долгосрочного бюджета 2014-2020 гг. Однако проблема ирландской границы оставалось нерешённой. Таким образом, одно из трёх ключевых требований ЕС осталось невыполненным. Несмотря на это Евросоюз решил поддержать британского премьер-министра, которая подвергалась дома сильной критике с разных сторон, и пошёл на определённые уступки. На саммите Европейского совета в декабре 2017 г. был отмечен значительный прогресс в ходе первой стадии переговоров с Великобританией и принято решение о переходе ко второму этапу для обсуждения будущего формата отношений. Стороны подписали Совместный доклад, в котором, однако, по требованию ЕС было прописано, что в отсутствие «уникального решения» по ирландской границе, будет применяться страховочное (backstop) решение, которое фактически оставляет Северную Ирландию в правовом поле ЕВР и Таможенного союза ${ }^{1}$. Таким образом Евросоюз, пойдя на встречу Т. Мэй, настоял на внесении в будущее соглашение положения, которое заведомо не могло найти поддержку у евроскептиков, ирландских юнионистов и других политических сил Соединённого Королевства, которые выступают за целостность страны.

Отвечая на просьбу британского правительства 29 января 2018 г., Совет министров иностранных дел 27 государств - членов Евросоюза принял решение предоставить Соединённому Королевству транзитный период ${ }^{2}$. Его продолжительность составит 21 месяц с момента выхода страны из состава Союза 29 марта 2019 г. и до 31 декабря 2020 г., когда закончится срок текущего семилетнего бюджета ЕС, который рассчитан с британским участием. В марте 2018 г. Мишель Барнье представил проект соглашения о выходе Великобритании из Европейского союза ${ }^{3}$, а на саммите Европейского совета лидеры ЕС дали зелёный свет второй стадии переговоров и приняли документ, в котором сформулировали свою позицию в отношении будущего двустороннего сотрудничества ${ }^{4}$.

В этот период активно обсуждалось, как именно должны быть оформлены соглашения между Великобританией и Евросоюзом. Часть экспертов полагала, что необходим общий текст о выходе и будущем формате отношений, в том числе в сфере безопасности, что облегчило бы ратификацию в Европарламенте, поскольку последний заинтересован в соблюдении прав граждан 5 . Непосредственные участники переговоров, однако, предполагали подписать

\footnotetext{
${ }^{1}$ Joint report from the negotiators of the European Union and the United Kingdom Government on progress during phase 1 of negotiations under Article 50 TEU on the United Kingdom's orderly withdrawal from the European Union. URL: https://ec.europa.eu/commission/sites/beta-political/files/joint_report.pdf.

${ }^{2}$ Council of the European Union. Annex to the Council Decision. Brussels, 29 January 2018. URL: http://www. consili um.europa.eu//media/32504/xt21004-ad01re02en18.pdf. BQE № 11949, 30.01.2018.

${ }_{3}$ European Commission. Draft Agreement on the withdrawal of the United Kingdom of Great Britain and Northern Ireland from the European Union and the European Atomic Energy Community. URL: https://ec.europa.eu/commissi on/sites/beta-political/files/draft_agreement_coloured.pdf.

${ }^{4}$ European Council (Art. 50) (23 March 2018) - Guidelines. URL: http://www.consilium.europa.eu/media/33458/23euco-art50-guidelines.pdf.

${ }^{5}$ Mortera-Martinez C. Plugging in the British: EU justice and home affairs. Centre for European Reform (CER), 2018. Научно-аналитический вестник ИЕ РАН, 2018, №6
} 
целый ряд соглашений, первым из которых должен стать документ об условиях «развода». Британская сторона, впрочем, настаивала на том ${ }^{1}$, что соглашения о выходе Великобритании из Европейского союза и о будущем формате отношений должны быть приняты не по отдельности, а пакетом, так как они взаимосвязаны между собой. Однако надеждам британского правительства не суждено было оправдаться.

Почти полгода переговоры буксовали, стороны не хотели отходить от своих «красных линий». Всё чаще стали говорить о том, что Британия может выйти без соглашения, что грозит хаосом и объективно не отвечает интересам обоих сторон. Вопрос ирландской границы стал центральным на переговорах. Сохранить границу прозрачной в условиях выхода Соединённого Королевства из Единого внутреннего рынка и Таможенного союза ЕС не представляется возможным, а применение страховочного решения нарушает внутреннее единство страны. К намеченному на октябрь 2018 г. саммиту соглашение о выходе не было готово, саммит по брекзиту перенесли на ноябрь. Новый министр по брекзиту Доменик Рааб ценой значительных уступок согласовал текст, но сам ушёл в отставку в знак несогласия с ним. В итоге в ноябре 2018 г. лидеры Евросоюза одобрили проект соглашения о выходе и подписали политическую декларацию о будущих отношениях. Дальше должна была пройти ратификация соглашения в британской Палате общин, затем в Европарламенте, и в заключение его должен одобрить Европейский совет. Однако в этом процессе случился сбой. Накануне голосования в британском парламенте Тереза Мэй его отменила, поскольку поняла, что соглашение не наберёт большинства голосов депутатов.

\section{Проблемы ратификации}

Что же не устраивает бо́льшую часть Палаты общин? Различные политические силы Британии имеют возражения против разных положений представленного соглашения о выходе Соединённого Королевства из $\mathrm{EC}^{2}$. Тори-евроскептики не согласны с тем, что Соединённое Королевство остаётся на неопределённое время в таможенном союзе с ЕС. Это означает, что Великобритания не сможет проводить самостоятельную внешнеторговую политику и заключать собственные соглашения с другими странами. Кроме того, оставаясь в Таможенном союзе ЕС, Британия обязуется придерживаться правил Евросоюза в таких сферах, как производственные, социальные и экологические стандарты, конкурентная политика, предоставление государственной помощи и НДС. Демократическую юнионистскую партию Северной Ирландии не устраивает, что даже если страховочное решение не вступит в силу, Северная Ирландия будет в большей степени, чем остальные части страны, подчиняться правилам ТС и ЕВР Евросоюза, чтобы сохранить прозрачную границу на острове. Таким образом, между Северной Ирландией и Великобританией будут введены определённые проверки товаров. Обе группы депутатов не собираются поддерживать проект соглашения.

Оппозиционные партии также выступают против, но по другим причинам. Лейбористы утверждают $^{3}$, что представленное соглашение не принесет выгоды Соединённому Королевству, и нужно проводить новые выборы и смягчать брекзит. Шотландские и валлийские нацио-

URL: https://cer.eu/sites/default/files/pbrief_plugin_jha_31.5.18.pdf.

${ }^{1}$ HM Government. The future relationship between the United Kingdom and the European Union. Jule 2018. URL: https://assets.publishing.service.gov.uk/government/uploads/system/uploads/attachment_data/file/725288/The_future_r elationship_between_the_United_Kingdom_and_the_European_Union.pdf.

${ }^{2}$ Agreement on the withdrawal of the United Kingdom of Great Britain and Northern Ireland from the European Union and the European Atomic Energy Community. URL: https://www.consilium.europa.eu/media/37099/draft_withdrawal_ agreement_incl_art132.pdf.

3 В партии существуют значительные разногласия относительно того, что именно может стать положительным результатом в брекзите.

Научно-аналитический вестник ИЕ РАН, 2018, №5 
налисты, а также либерал-демократы выступают либо в целом против выхода из ЕС, либо за применение «норвежской» модели сотрудничества, и также против соглашения Терезы Мэй. Часть проевропейски настроенных депутатов от разных партий выступает против соглашения и за проведение повторного референдума.

В такой ситуации отмена голосования в декабре 2018 г. не выглядит безумным шагом со стороны премьер-министра. Выиграв время, она может надеяться на результаты разъяснительной работы среди депутатов и перебежчиков из других партий. Ведь, если соглашение не пройдет ратификацию в британском парламенте, то времени на согласование нового не будет, а требования Европейского союза останутся прежними.

\section{Выводы}

В ходе переговоров Европейский союз смог добиться всех поставленных им задач, а Соединённому Королевству пришлось идти на серьезные уступки. Это связано с рядом причин.

Во-первых, государства-члены и институты Евросоюза выработали консолидированную позицию и твёрдо её придерживались, демонстрируя столь редкое в ЕС единство. Напротив, в британском правительстве, партии тори, в парламенте и в обществе в целом наблюдаются принципиальные разногласия по вопросу брекзита, а позиции премьер-министра неустойчивы и постоянно подвергаются критике с разных сторон.

Во-вторых, проблема границы на острове Ирландия, на тех условиях, что изначально обозначили стороны, не может быть решена в принципе. Очевидно, что здесь необходимо было идти на уступки. Но правила функционирования ЕВР и ТС делают здесь уступки со стороны Европейского союза невозможными, а обязательство сохранить границу прозрачной заставило Терезу Мэй согласиться на сохранение страны в Таможенном союзе с ЕС.

\section{Список литературы}

Ананьева Е.В. Брекзит: предыстория и причины // Международная жизнь. № 2, 2018. С. 22-35.

Ананьева Е.В. Дебаты в британском парламенте по Соглашению с ЕС. Аналитические записки Института Европы РАН. № 52(148), 2018. URL: http://instituteofeurope.ru/images/up loads/analitika/2018/an148.pdf.

Бабынина Л.О. Великобритания и ЕС: перспективы сотрудничества // Современная Европа, № 4, 2018. C. 57-67.

\section{References}

Agreement on the withdrawal of the United Kingdom of Great Britain and Northern Ireland from the European Union and the European Atomic Energy Community. URL: https://www. consili um.europa.eu/media/37099/draft_withdrawal_agreement_incl_art132.pdf.

Ananieva E.V. Brekzit: predystoriya i prichiny. Mezhdunarodnaya zhizn’. № 2, 2018. P. 22-35.

Ананьева Е.B. Debaty v britanskom parlamente po Soglasheniyu s ES. Analiticheskie zapiski Instituta Evropy RAN. № 52(148), 2018. URL: http://instituteofeurope.ru/images/uploads/analitika/ 2018/an148.pdf.

Babynina L.O. Velikobritaniya i ES: perspektivy sotrudnichestva. Sovremennaya Evropa. № 4, 2018. P. 57-67.

Council of the European Union. Annex to the Council Decision. Brussels, 29 January 2018. URL: http://www.consilium.europa.eu//media/32504/xt21004-ad01re02en18.pdf.

European Commission. Draft Agreement on the withdrawal of the United Kingdom of Great Britain and Northern Ireland from the European Union and the European Atomic Energy Community. URL: https://ec.europa.eu/commission/sites/beta-political/files/draft_agreement_coloured.pdf. 
European Council (Art. 50) (23 March 2018) - Guidelines. URL: http://www.consilium.europa. eu/media/33458/23-euco-art50-guidelines.pdf.

European Council (Art. 50) guidelines following the United Kingdom's notification under Article 50 TEU. URL: http://www.consilium.europa.eu/en/press/press-releases/2017/04/29-euco-brexit-guidelines/

Gostyńska-Jakubowska A. Brexit maze: The role of EU institutions in the negotiations. Centre for European Reform (CER). 2017. London. URL: https://cer.eu/sites/default/files/pb_brexit_insti tutions_5.7.17.pdf.

HM Government. The future relationship between the United Kingdom and the European Union. Jule 2018. URL: https://assets.publishing.service.gov.uk/government/uploads/system/uploads/ attachment_data/file/725288/The_future_relationship_between_the_United_Kingdom_and_the_European_U nion.pdf.

Joint report from the negotiators of the European Union and the United Kingdom Government on progress during phase 1 of negotiations under Article 50 TEU on the United Kingdom's orderly withdrawal from the European Union. URL: https://ec.europa.eu/commission/sites/beta-political/ files/joint_report.pdf.

Mortera-Martinez C. (2018) Plugging in the British: EU justice and home affairs. Centre for European Reform (CER). URL: https://cer.eu/sites/default/files/pbrief_plugin_jha_31.5.18.pdf.

Plan for Britain. The government's negotiating objectives for exiting the EU: PM speech. URL: https://www.gov.uk/government/speeches/the-governments-negotiating-objectives-for-exiting-the-eu-pmspeech.

The European Council. Infographics - brexit process URL: http://www.consilium.europa.eu/ en/infographics/brexit-process/

The European Parliament. Red lines on brexit negotiations. URL: http://www.europarl.europa. eu/news/en/headlines/priorities/brexit/20170329IPR69054/red-lines-on-brexit-negotiations

\section{Agreement on exit of Britain from the EU: prospects for ratification}

Author. Ludmila Babynina, Candidate of Sciences (Politics), Leading Research Associate, Head of the Centre for Political Integration, Department of European Integration Studies, Institute of Europe, Russian Academy of Sciences. Address: 11-3, Mokhovaya str., Moscow, Russia, 125009. Associate Professor, Faculty of World Politics, Lomonosov Moscow State University. E-mail: lbabynina@yandex.ru.

Abstract. Negotiations on the terms of the exit of the United Kingdom from the European Union lasted more than a year and a half. Both sides made concessions to achieve the desired result. As expected, the European Union was able to meet almost all of its requirements, and Britain had to retreat from part of its original requirements. However, the agreed text has caused discontent in the British political community. As a result, the prospects for its ratification in the House of Commons remain very vague. Refusal to ratify threatens political chaos for the UK and a possible exit «without a deal» which objectively does not meet the interests of the parties.

Key words: Brexit, European Union, United Kingdom, Irish border, withdrawal agreement, House of Commons.

DOI: http://dx.doi.org/10.15211/vestnikieran620181419

Научно-аналитический вестник ИЕ РАН, 2018, №5 